\title{
ESTRUTURAS DOBRADAS DO QUADRILÁTERO FERRÍFERO EM PERFIS GEOLÓGICOS DO SÉCULO XIX
}

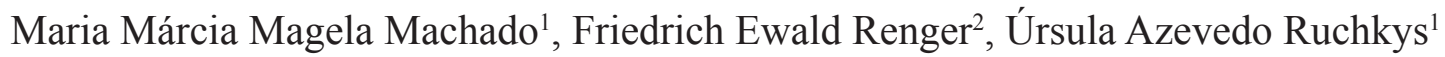

\begin{abstract}
RESUMO
Na primeira metade do século XIX houve um acréscimo significativo de conhecimento sobre a geologia do Quadrilátero Ferrífero advindo do trabalho de naturalistas-viajantes e de especialistas europeus em exploração mineral que empreenderam pesquisas nesta região. Merecem atenção especial, principalmente, os trabalhos de Virgil von Helmreichen e Aimé Pissis pelo cunho prioritariamente geológico. As memórias geológicas de Helmreichen, geólogo e engenheiro de minas austríaco, incluem um perfil não retilíneo entre a cidade do Rio de Janeiro e o rio Santo Antônio no sertão do São Francisco. Na região do Quadrilátero Ferrífero, o detalhamento do acamamento entre Tejuco e Caeté registra a estrutura dobrada conhecida hoje como Sinclinal de Gandarela. Pissis publicou em 1848 sua Mémoire sur la position géologique des terraines de la partie australe du Brésil; entre as pranchas que acompanham a publicação está um perfil geológico de cerca de $12 \mathrm{~km}$ que detalha o acamamento entre o Pico do Itacolomi, ao sul, até a Serra de Antônio Pereira, ao norte. A repetição das camadas com inversão do mergulho de sul para norte caracteriza claramente o dobramento do Anticlinal de Mariana; um avanço considerável sobre as seções apresentadas por Eschwege em 1811 e 1816.
\end{abstract}

\begin{abstract}
During the first half of the 19th century a significant amount of geological knowledge concerning the Quadrilátero Ferrífero was produced by European naturalists and travellers as well as experts in mineral exploration. Among them the work of Virgil von Helmreichen, an Austrian geologist and mining engineer, and the French naturalist Aimé Pissis are of special interest. The memories of Helmreichen include a profile from Rio de Janeiro in the South to the Rio Santo Antonio in the interior of the São Francisco river basin to the North, passing over the Quadrilátero Ferrífero. Near Caeté it shows clearly the inversion of the dip of bedding, indicating a folded structure, today known as Gandarela Syncline. Pissis published in 1848 his Mémoire sur la position géologique des terraines de la partie australe du Brésil; one of the accompanying figures represents a $12 \mathrm{~km}$-section between the Itacolumi Peak in the South and the Serra de Antonio Pereira to the North, which details bedding and dip of rocks. Repetition of strata with inversion of the dip caracterizes clearly the folded structure of the Mariana Anticline, showing both examples a considerable progress compared with the sections of von Eschwege from 1811 and 1816.
\end{abstract}

\section{INTRODUÇÃO}

Com a abertura dos portos brasileiros às nações amigas em 1808, o Brasil, que tanto interesse despertava nos naturalistas, passou a ser acessível para pesquisas. Não havia mais motivo para o sigilo territorial que, até então, era imposto pela metrópole. Ferri \& Motoyama (1981) classificam esta iniciativa como uma ruptura na história das Geociências no Brasil na medida em que ela possibilitou a entrada de missões científicas européias e com elas um acréscimo significativo de conhecimento.

Em relação à contribuição ao entendimento da geologia do Quadrilátero Ferrífero, um destaque especial deve ser dado ao Barão de Eschwege. O fato dele ter residido no Brasil por 11 anos, entre 1810 e 1821, a serviço da Coroa portuguesa, o distingue de outros naturalistas estrangeiros que aqui estiveram de passagem. Eschwege foi encarregado, por D. João VI, de reanimar a decadente mineração de ouro e implementar a indústria siderúrgica. Esta particularidade lhe permitiu observações mais detalhadas e aprofundadas na investigação da natureza, principalmente da Capitania de Minas Gerais, onde ele passou a maior parte do tempo. Em linhas gerais, Eschwege delineou o sistema orográfico da região e propôs uma ordenação estratigráfica para seus terrenos com quatro divisões nos moldes da escola netunista werneriana (Renger, 2005). Com ele surgem as primeiras representações gráficas da geologia da área. Uma análise dos perfis produzidos por Eschwege, entre ca. de 1811 e 1816, evidencia a evolução de seu conhecimento sobre a geologia dos terrenos percorridos. O que chama atenção no perfil de 1811 é o fato das camadas estarem dispostas horizontalmente, apesar da constatada obliqüidade, obedecendo a um ordenamento ideal, com os estratos mais recentes no topo, refletindo a influência da escola netunista werneriana. Diferentemente do anterior, o perfil de 1816 apresenta a direção preferencial dos estratos constituídos destacada, principalmente, pela alternância das chamadas rochas primitivas. O padrão desta representação se assemelha bastante com o da seção geológica elaborada por Lehmann para a Thuringia, em 1759, cuja teoria sobre a formação das montanhas incluía as camadas oblíquas ou perpendiculares dos chamados montes primitivos ("Urgebirge").

Entretanto, o registro de estruturas dobradas só viria mais tarde nos perfis que detalham a estratigrafia das formações de trechos do Quadrilátero Ferrífero produzidos por Virgil von Helmreichen (1805-1852), 
geólogo e engenheiro de minas austríaco, e pelo geólogo e cartógrafo francês, Aimé Pissis (1812-1889).

\section{O SINCLINAL DE GANDARELA POR HELMREICHEN}

Virgil von Helmreichen, chegou ao Brasil em 1836 para trabalhar na Mina do Morro das Almas, localizada cerca de $5 \mathrm{~km}$ a sudoeste do Pico de Itabirito, pertencente a companhia inglesa The Brazilian Company Ltda ${ }^{1}$. Trabalhou ainda nas minas vizinhas Cata Branca e Aredes desta mesma companhia. Prestou serviços também para a Imperial Brazilian Mining Association nas minas de Gongo Soco, Antônio Pereira e Cata Preta e em outras como a Morro Velho da St. John D'el Rey Mining Company. O trabalho em Gongo Soco está registrado num relatório, de dezembro 1840, preparado para a gerência local da mina e para os superiores da Imperial Brazilian Mining Association em Londres, no qual seu nome encabeça a lista de autores.
Os rendimentos financeiros de seu trabalho nas companhias de mineração, de estudo das mineralizações auríferas e viabilidade econômica de exploração, possibilitaram a realização de suas ambições científicas. Helmreichen fez viagens de pesquisas geológicas principalmente para estudo das regiões diamantíferas e auríferas do Brasil.

Sobre o resultado de suas pesquisas na região aurífera de Minas Gerais, hoje Quadrilátero Ferrífero, foi publicado um relatório de viagem, em Viena, no ano de $1847^{2}$. Este relato foi organizado por seu amigo Hocheder, secretário da Imperial e Real Diretoria Central das Minas da Áustria, a partir de extratos das correspondências a ele enviadas por Helmreichen. Não há no texto considerações sobre a gênese ou idade das formações, o "Relatório de Viagens em Minas Gerais" se restringe, basicamente, a indicação dos locais visitados com descrição das formações rochosas (Machado, 2009). Entretanto, existem três perfis geológicos manuscritos no Arqivo da Academia

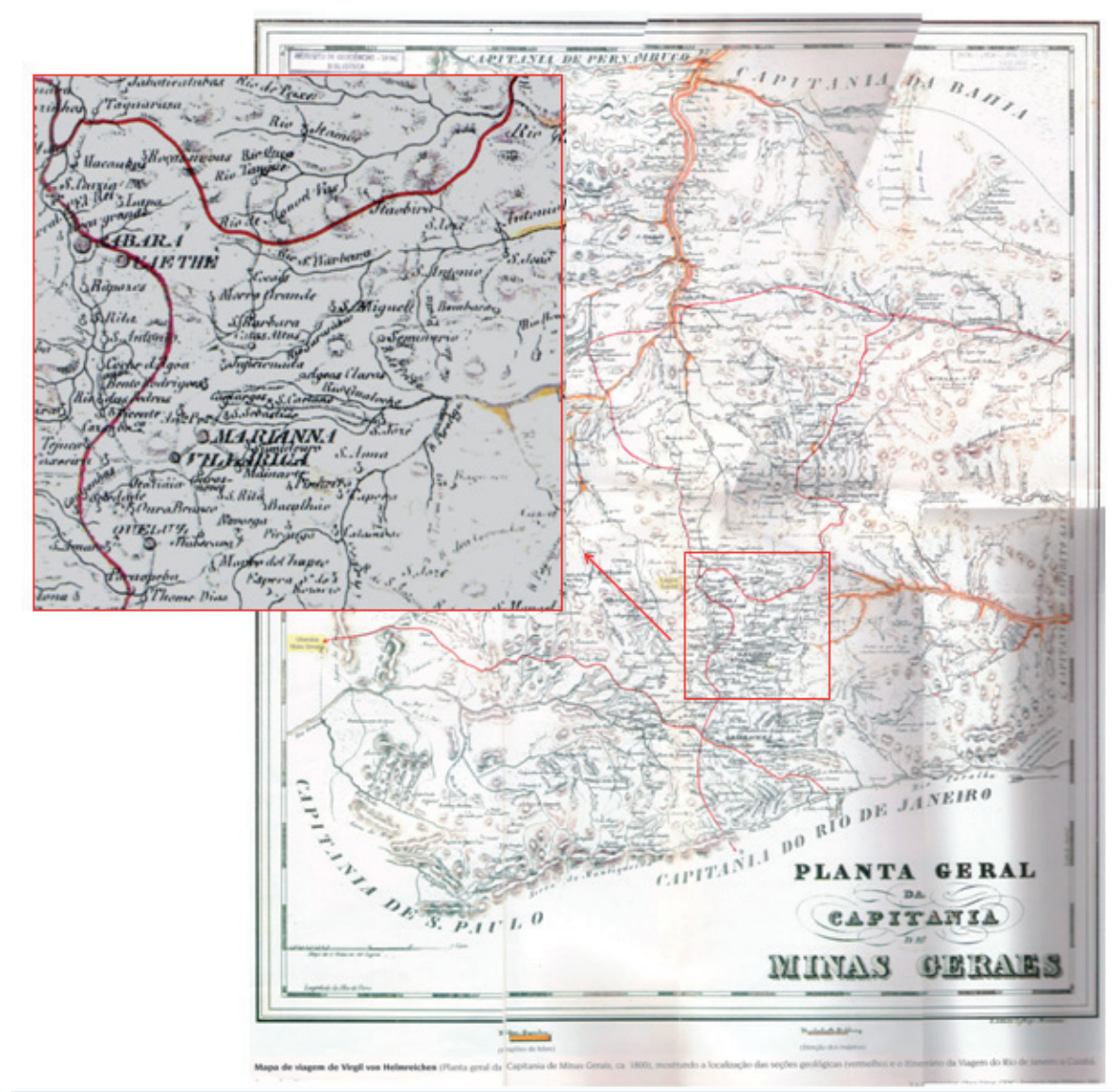

Figura 1 - Mapa mostrando os trajetos de Helmreichen que deram origem aos perfis geológicos (Helmreichen, 1846). No detalhe o percurso na área do atual Quadrilátero Ferrífero.

\footnotetext{
1 “Os ingleses, logo após a independência do Brasil, perceberam as chances de fundar sociedades anônimas no país. Depois de levantar capital por meio de ações em Londres, adquiriram lavras promissoras, sobretudo em Minas Gerais". Foram adquiridas por companhias inglesas as minas de Gongo Soco, Cata Preta, Antônio Pereira, Morro Velho, Cata Branca e ainda minas em Cocais, Brucutu e Cuiabá (Renger in: Helmreichen, 2002).

${ }^{2}$ Publicado nos Berichte über die Mitthheilungen von Freunden der Naturwissenchaften in Wien (ed. W. Haidinger), n. 10, p-137-151, fev. 1847.
} 
de Ciências de Viena que cortam a Província de Minas, a saber: Seção Geológica desde a aldeia dos botocudos de Jataí, no vale do Rio Jequitinhonha, até o Comércio do Rio Santo Antônio, no Sertão do Rio São Francisco passando pela Serra do Grão Mogol; Seção Geológica desde a barra do Rio Araçuaí, no Jequitinhonha até Lagoa Santa, passando por Diamantina e a Seção geológica desde o Rio de Janeiro até o Comércio do Rio Santo Antônio, no Sertão do São Francisco, com cerca de 100 léguas de comprimento, aproximadamente $600 \mathrm{~km}$, que corta o Quadrilátero Ferrífero fazendo uma grande curva na região de Caeté e Sabará para depois seguir para Itabira. A Figura 1 apresenta os trajetos de Helmreichen com destaque para o trecho percorrido no Quadrilátero Ferrífero.

Helmreichen incluiu todas as formações do Quadrilátero Ferrífero num grupo que denominou genericamente de Grupo dos Gnaisses. A representação do Quadrilátero Ferrífero no perfil geológico de Helmreichen inicia, de sul para norte, com os granitos do Arraial do Redondo (Alto Maranhão) e Congonhas, seguindo para o xisto argiloso talcífero intercalado com formações ferríferas, itacolomito e itabirito, na região do Pires (Figura 2).

É exatamente no trecho seguinte, no detalhamento do acamamento entre o Pires e Caeté, que está representada, de forma clara e inédita, a estrutura dobrada conhecida hoje como Sinclinal de Gandarela. A figura 3 apresenta este trecho: de sul para o norte, partindo de Tejuco, lugarejo ao norte de Congonhas cuja denominação já desapareceu na toponímia local, aparece o granito do Bação (rosa) e o Rio das Velhas, continuando surge o xisto argiloso com talco (amarelo) e intercalações de itacolumito (laranja), em seguida uma camada de itabirito quartzoso (lilás), todas mergulhando para Norte caracterizando o flanco sul do Sinclinal. Depois de uma faixa de itabirito argiloso (verde) o acamamento se repete com inversão do mergulho, agora para o Sul constituindo o flanco norte do Sinclinal (Gongo Soco), terminando no granito do Domo de Caeté (rosa).

\section{O ANTICLINAL DE MARIANA POR PISSIS}

Aimé Pissis chegou ao Brasil por volta de 1836 e excursionou cinco anos fazendo observações geológicas

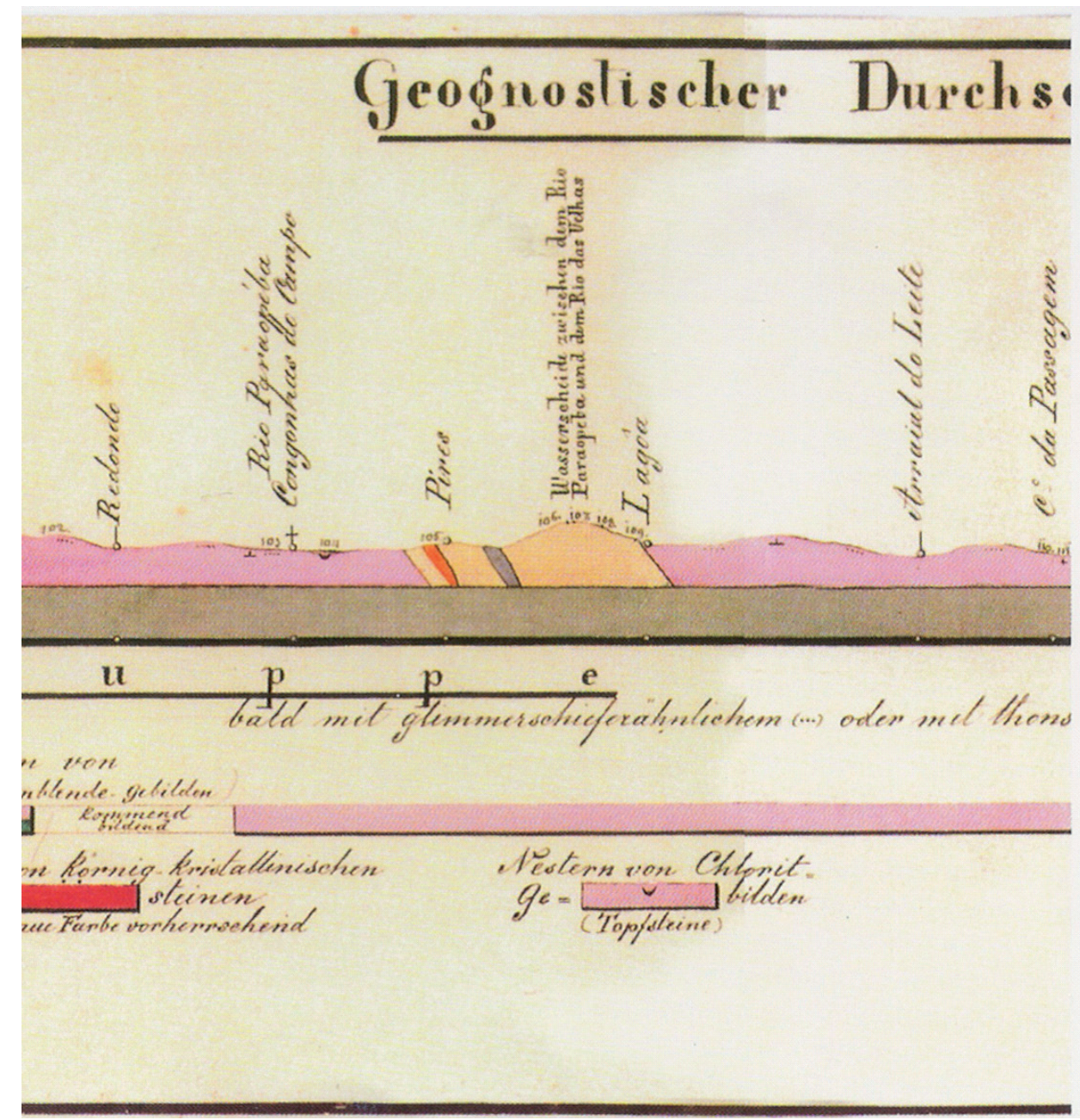

Figura 2 - Trecho do Perfil geológico entre o Rio de Janeiro e o comércio no Rio Santo Antônio no sertão do São Francisco quando o traçado entra na atual área do Quadrilátero Ferrífero pelo sul, próximo ao município de Congonhas (Helmreichen, 1846) 


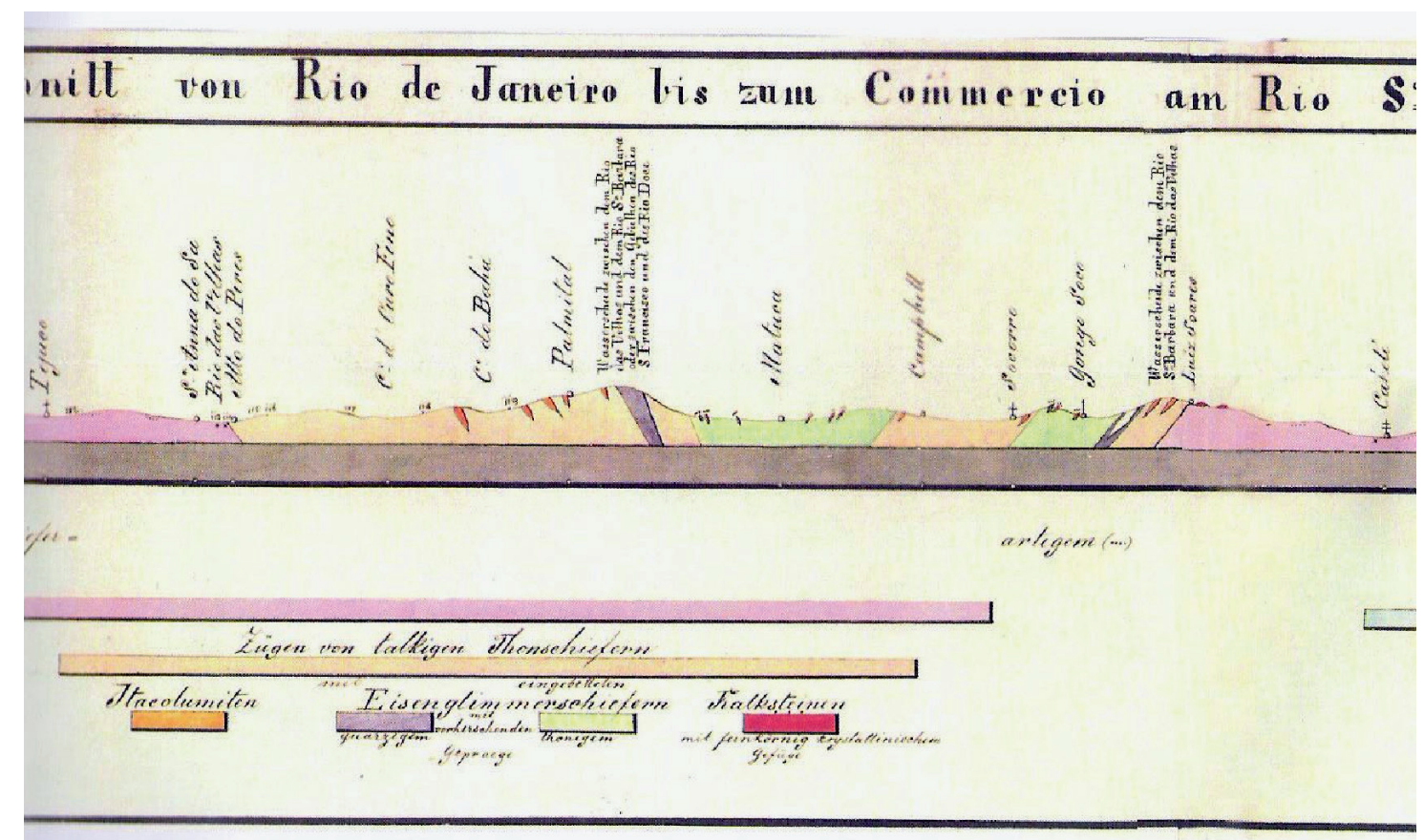

Figura 3 - Representação do Sinclinal do Gandarela no Perfil geológico entre o Rio de Janeiro e um comércio no Rio Santo Antônio no sertão do São Francisco. (Helmreichen,1846)

da foz do rio São Francisco, ao norte, até Paranaguá, ao sul, e do litoral até o rio São Francisco e rio Paraná, a oeste. Mesmo quando os Andes concentravam grande parte da atenção dos geólogos viajantes, principalmente depois dos relatos de Humboldt sobre sua viagem, por causa das enormes soerguimentos ali ocorridos e dos fenômenos vulcânicos, Pissis justificou seu interesse em estudar a geologia do Brasil por acreditar que a antiguidade de seus terrenos, expressa na regularidade e simplicidade de seu relevo, podia ser uma peça esclarecedora da geologia da América. Sustentava que nesses terrenos, onde "perturbações recentes" não alteraram completamente ou mesmo consideravelmente o relevo, era possível estudar os eventos anteriores pelos traços que ali ainda estavam impressos.

Em 1842 foi lido na Academia de Ciências de Paris seu trabalho intitulado Mémoire sur la position géologique des terraines de la partie australe du Brésil, publicado em 1848. Na introdução ele explicita a necessidade de reunir as observações relativas à composição dos terrenos e sua posição relativa com aquelas que dizem respeito às formas que caracterizam o relevo, o estudo das cadeias de montanhas, a direção das camadas e sua inclinação, para imprimir a clareza necessária à exposição. É então apresentada no artigo uma classificação para os terrenos geológicos percorridos e um estudo dos movimentos orogênicos identificados.

Quanto à classificação, vale observar o ponto de vista de Pissis no que tange à classe das rochas xistosas do grupo primitivo, por se tratar de sua descrição das seqüências supracrustrais dobradas do Quadrilátero Ferrífero. Pissis apresenta sete divisões para as rochas xistosas: os quartzitos inferiores que repousam imediatamente sobre o gnaisse que, em alguns pontos, atingem uma espessura de $800 \mathrm{~m}$, hoje Formação Moeda; recobertos pelos xistos inferiores que em algumas localidades são bastante friáveis e o ferro é substituído por um xisto branco pulverulento que abriga cristais de quartzo, topázios e euclásios, provavelmente Formação Batatal; em seguida outra camada de quartzito que se distingue da inferior por sua estrutura mais xistosa que lhe imprime uma estrutura laminar muito fina não passando nunca a granular, Grupo Piracicaba; depois o itabirito, dominantemente xistoso, de espessura variadíssima, com a jacutinga ocupando normalmente as partes inferiores desta formação que é a mais rica em ferro e em ouro abrigando as minas mais importantes, o Greenstone Belt Rio das Velhas; os calcários deste estágio são freqüentemente granulares mais raramente compactos e são encontrados entre os quartzitos médios e os itabiritos em alguns poucos pontos; os xistos superiores muito mais friáveis que os inferiores repousam imediatamente sobre os itabiritos e, por último, uma camada potente de quartzito cuja espessura varia de 400 a $500 \mathrm{~m}$ aparecendo nos pontos mais elevados de Minas Gerais como o Itacolomi, a Serra do Caraça e o Morro do Itambé, Grupos Itacolomi e Caraça e Supergrupo Espinhaço (Machado, 2009).

Para completar a descrição acompanham um esboço geológico da região aurífera de Minas Gerais e sete perfis geológicos. Entre eles está um perfil, de cerca de $12 \mathrm{~km}$, que detalha o acamamento entre o Pico do Itacolomi, ao sul, até a Serra de Antônio Pereira, ao norte, passando por Ribeirão do Carmo, Ouro Preto, Serra da Cachoeira (Figura 4).

Neste perfil a repetição das camadas com inversão do mergulho, de sul para norte entre Ouro Preto e o Rio Gualaxo, caracteriza nitidamente o dobramento do Anticlinal de Mariana: as camadas sobrepostas de 


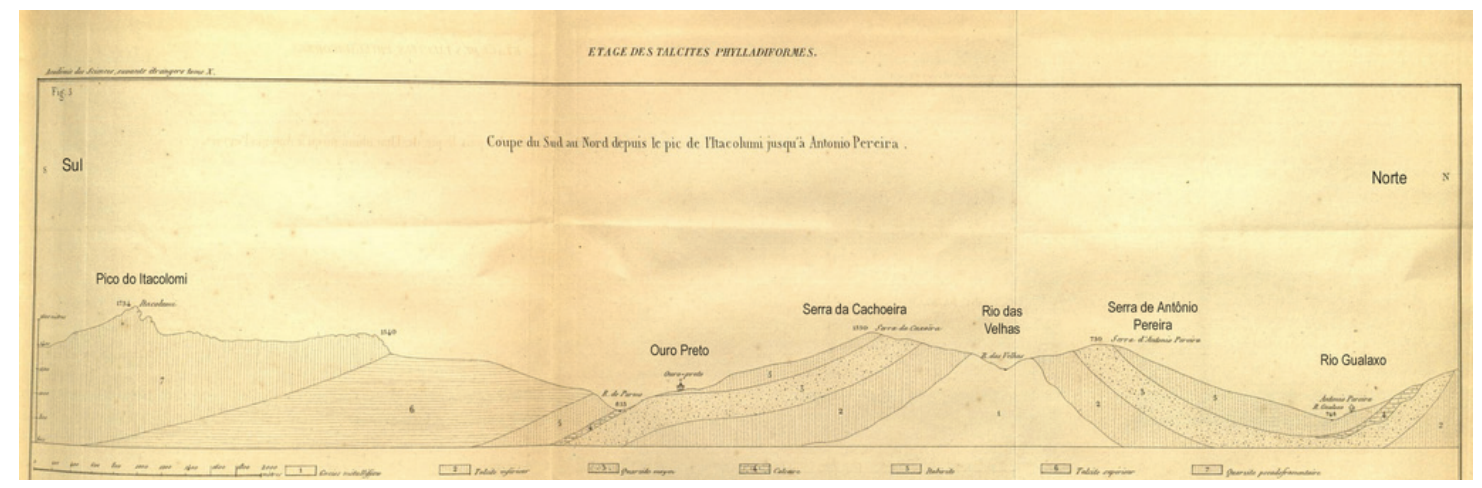

Figura 4 - Corte de sul para norte do Pico do Itacolomi até a Serra de Antônio Pereira (Pissis, 1848)

xisto, quartzito e itabirito mergulhando para o sul na Serra da Cachoeira, caracterizando o flanco sul do Anticlinal, se repetem com inversão do mergulho para norte, depois do Rio das Velhas, na Serra de Antônio Pereira constituindo o flanco norte do Anticlinal.

\section{CONSIDERAÇÕES FINAIS}

A cartografia é uma forma eficiente de comunicação dos conceitos geológicos e há muito vem sendo utilizada com tal finalidade. As representações gráficas inclusive revelam mais do que feições geológicas, elas são produtos de uma circunstância histórica, portanto são imagens tanto do estado da arte da geologia como da própria cartografia geológica.

Os perfis elaborados por Helmreichen e Pissis são os primeiros registros de estruturas dobradas no Quadrilátero Ferrífero. Estas representações, se comparadas àquelas produzidas por Eschwege aproximadamente trinta anos antes, revelam a evolução da base epistemológica da ciência geologia, o acréscimo de conhecimento sobre a geologia do Quadrilátero Ferrífero e ainda a consolidação do perfil como instrumento eficaz de visualização da geologia.

\section{REFERÊNCIAS BIBLIOGRÁFICAS}

ESCHWEGE W.L. VON 1811 Carta petrográfica e orográfica com hum perfil das rochas de Villa Rica para o Arrayal do Tejuco e idem do Arrayal do Tejuco pelo Caminho do Sabará para Villa Rica. Arqu. Hist. do Exército (RJ), manuscrito

FERRI M.G. E MOTOYAMA S. 1981. História das ciências no Brasil. EPU/EDUSP, São Paulo, v. 3, 467 p.

HELMREICHEN V. VON 1846. Obras várias de Virgil von Helmreichen (1805-1852): Contribuições à Geologia do Brasil. Trad. Elisabeth C. Renger e Friedrich E. Renger. Fundação João Pinheiro, Belo Horizonte, ed. 2002,140 p.

MACHADO M.M.M. 2009. Construindo a imagem geológica do Quadrilátero Ferrífero: conceitos e representações. Tese de Doutorado em Geologia, Universidade Federal de Minas Gerais. 238p.

PISSIS A. 1848. Mémoire sur la position géologique des terrains de la partie australe du Brésil, et sur les soulèvements qui, à diverses époques, ont changé le relief de cette contrée. Académie des Sciences de L'Institut National de France, Paris, Memoires t. X, p. 353-413.

RENGER, F.E. 2005. O quadro geognóstico do Brasil de Wilhelm Ludwig von Eschwege: breves comentários à sua visão da geologia no Brasil. Geonomos, Belo Horizonte, XIII, p. 91-95. 